Article

\title{
"Artificial Wood" Lignocellulosic Membranes: Influence of Kraft Lignin on the Properties and Gas Transport in Tunicate-Based Nanocellulose Composites
}

\author{
Ievgen Pylypchuk ${ }^{1, *(\mathbb{D})}$, Roman Selyanchyn ${ }^{2, *} \mathbb{0}$, Tetyana Budnyak ${ }^{3}$, Yadong Zhao ${ }^{1}$, Mikael Lindström ${ }^{1,4}$, \\ Shigenori Fujikawa ${ }^{2}$ and Olena Sevastyanova ${ }^{1,4}$
}

1 Division of Wood Chemistry and Pulp Technology, Department of Fiber and Polymer Technology, School of Chemistry, Biotechnology and Health, KTH Royal Institute of Technology, Teknikringen 56-58, 10044 Stockholm, Sweden; yadong@kth.se (Y.Z.); mil@kth.se (M.L.); olena@kth.se (O.S.)

2 WPI International Institute for Carbon-Neutral Energy Research (WPI-I2CNER) Kyushu University, Ito Campus, 744 Motooka, Nishi-ku, Fukuoka 819-0395, Japan; fujikawa.shigenori.137@m.kyushu-u.ac.jp

3 Department of Materials and Environmental Chemistry, Stockholm University, Svante Arrhenius väg 16C, 10691 Stockholm, Sweden; tetyana.budnyak@mmk.su.se

4 Wallenberg Wood Science Center, Department of Fiber and Polymer Technology, School of Chemistry, Biotechnology and Health, KTH Royal Institute of Technology, Teknikringen 56-58, 10044 Stockholm, Sweden

* Correspondence: ievgenpy@kth.se (I.P.); romanselyanchyn@i2cner.kyushu-u.ac.jp (R.S.)

\section{check for} updates

Citation: Pylypchuk, I.; Selyanchyn, R.; Budnyak, T.; Zhao, Y.; Lindström, M.; Fujikawa, S.; Sevastyanova, O. "Artificial Wood" Lignocellulosic Membranes: Influence of Kraft Lignin on the Properties and Gas Transport in Tunicate-Based Nanocellulose Composites. Membranes 2021, 11, 204. https://doi.org/10.3390/

membranes11030204

Academic Editor: Isabel C. Escobar

Received: 25 February 2021

Accepted: 10 March 2021

Published: 13 March 2021

Publisher's Note: MDPI stays neutral with regard to jurisdictional claims in published maps and institutional affiliations.

Copyright: (c) 2021 by the authors. Licensee MDPI, Basel, Switzerland. This article is an open access article distributed under the terms and conditions of the Creative Commons Attribution (CC BY) license (https:// creativecommons.org/licenses/by/ $4.0 /)$.
Abstract: Nanocellulose membranes based on tunicate-derived cellulose nanofibers, starch, and $\sim 5 \%$ wood-derived lignin were investigated using three different types of lignin. The addition of lignin into cellulose membranes increased the specific surface area (from 5 to $\sim 50 \mathrm{~m}^{2} / \mathrm{g}$ ), however the fine porous geometry of the nanocellulose with characteristic pores below $10 \mathrm{~nm}$ in diameter remained similar for all membranes. The permeation of $\mathrm{H}_{2}, \mathrm{CO}_{2}, \mathrm{~N}_{2}$, and $\mathrm{O}_{2}$ through the membranes was investigated and a characteristic Knudsen diffusion through the membranes was observed at a rate proportional to the inverse of their molecular sizes. Permeability values, however, varied significantly between samples containing different lignins, ranging from several to thousands of barrers $\left(10^{-10} \mathrm{~cm}^{3}(\mathrm{STP}) \mathrm{cm} \mathrm{cm}^{-2} \mathrm{~s}^{-1} \mathrm{cmHg}^{-1} \mathrm{~cm}\right)$, and were related to the observed morphology and lignin distribution inside the membranes. Additionally, the addition of $\sim 5 \%$ lignin resulted in a significant increase in tensile strength from $3 \mathrm{GPa}$ to $\sim 6-7 \mathrm{GPa}$, but did not change thermal properties (glass transition or thermal stability). Overall, the combination of plant-derived lignin as a filler or binder in cellulose-starch composites with a sea-animal derived nanocellulose presents an interesting new approach for the fabrication of membranes from abundant bio-derived materials. Future studies should focus on the optimization of these types of membranes for the selective and fast transport of gases needed for a variety of industrial separation processes.

Keywords: nanocellulose; lignin; nanocomposites; gas separation; biopolymer membrane

\section{Introduction}

Cellulose and lignin, the two major components of higher plants, are the most abundant polymers on earth. Nanocellulose is a form of cellulosic material that can be obtained from the smallest organisms (i.e., bacteria) to the largest high plants (i.e., trees). Due to its combination of high mechanical strength and low density, it is expected to be used in a variety of emerging applications, such as in environmentally friendly composite materials, films, coatings, and membranes in the food and pharmaceutical industries and for energy applications [1-3]. Taking into their account natural origin, renewable character, and biodegradability, biomass-derived materials are an important research direction, with the aim of substituting the multitude of materials obtained from fossil fuels. The preparations and applications of nanomaterials from biomass are dominated by the use of mechanochem- 
ical methods to separate the components followed by processing to provide the materials with specific nanofeatures (e.g., morphology, particle size, or crystallinity) [4,5].

Nanocellulose has considerable potential to extend the applications of conventional cellulose for environmental remediation and filtration purposes (i.e., conventional paper filters) and advanced gas separation (cellulose-derived membranes). The material is versatile and can be used in the form of powders, gels, films, or membranes. For instance, Wei et al. reported nanocellulose and lignin-derived carbon aerogels with a high $\mathrm{CO}_{2}$ adsorption capacity of up to $5.23 \mathrm{mmol} \mathrm{g}^{-1}$ at $273 \mathrm{~K}$ and $100 \mathrm{kPa}$ [6]. Using the combination of graphene oxide, a polymer of intrinsic microporosity (PIM-1), with cellulose acetate, Allamar et al. constructed nanocomposite hydrogels to increase the adsorption of insecticides [7]. In recent work, Zheng et al. combined TEMPO-modified cellulose nanocrystals with oxidized carbon to prepare composite films for selective adsorption of the rare-earth element Dy (III) [8]. Due to its low cost, cellulose can also be used as an affordable support for more advanced membrane fabrication, for example grafting of polymer brushes [9].

Cellulosic materials also have a long history in membranes. Recently, a microfibrillated nanocellulose (MFC) membrane showed outstanding selectivity in the separation of $\mathrm{CO}_{2}$ from $\mathrm{N}_{2}$ and $\mathrm{CH}_{4}$ when a highly humidified gas stream was tested [10]. Bayer et al. [11,12] used different types of nanocellulose in proton exchange membranes (PEM) for fuel cell applications, demonstrating a high gas barrier in dry conditions that was much different from the conventional cellulose-based membranes. Both cellulose nanofiber (CNF) and cellulose nanocrystal (CNC) membranes showed significantly lower gas permeabilities than cellulose membranes. Gas transport rates for small gases $\left(\mathrm{H}_{2}, \mathrm{CO}_{2}, \mathrm{~N}_{2}\right.$, and $\left.\mathrm{O}_{2}\right)$ were more than two orders of magnitude smaller [11] for CNF than for conventional cellulose and state-of-art PEMs (e.g., Nafion). In another application, nanocellulose can be used for filtration membranes similar to conventional paper filters, but with more precise control over the pore sizes. Quellmalz and Mihranyan [13] cross-linked Cladophora cellulose with citric acid for size exclusion filters that were able to remove particles as small as $20 \mathrm{~nm}$ from a dispersion, showing that nanofiltration applications for virus filtration can be developed, although the structure-property relations in a variety of nanocellulose types need further study.

In plants, cellulose is combined with lignin [14] and hemicelluloses. Lignin, which is also available in large quantities, enhances plant cell wall rigidity and hydrophobic properties and promotes mineral transport through the vascular bundles in plants $[15,16]$. In the process of paper production from wood, lignin is usually degraded and removed and the cellulose fibers are separated and retained. Once dissolved in cooking liquor, the lignin is generally used as a low-cost fuel, however separation and upgrading, especially of kraft lignin, are now emerging as important topics [17], and the market is expected to reach 3.5-14 Mt/year [18], providing an additional 5-10\% revenue for the pulp mills.

A beneficial synergistic effect of mixing lignin and cellulose in different applications was demonstrated in a review by Balakshin et.al. [17]. The incorporation of lignin as a component of cellulose membranes was reported by Farooq et.al., whereby lignin-containing membranes were applied to absorb UV radiation [19]. Dou et al. reported the manufacture of highly hydrophobic films from willow bark lignocellulose [20], and physisorption studies of $\mathrm{CO}_{2}$ capture by lignin-derived carbons have also been reported [6,21,22].

Considering the abundant resources of nanocellulose and lignin, which are low-cost and environmentally friendly natural polymers, and the established record of conventional cellulose membranes for certain gas separation applications, the study of their gas transport is of great importance. The understanding of the synergy of the components in recombined formulations is still unclear. In this study, we provide an initial assessment of the gas transport through nanocellulose membranes containing a small fraction $(\sim 5 \mathrm{wt} \%)$ of a woodderived kraft lignin. Purified and well-characterized lignins from three different sources (hardwood, softwood) and nanocellulose from tunicate (Ciona intestinalis) were used to create materials in which wood-derived lignin was combined with sea-animal derived 
cellulose. The membranes can, thus, be considered to be a new type of nanocellulose paper within the framework of re-assembled or artificial wood.

\section{Materials and Methods}

\subsection{Materials}

The prehydrolysis-kraft cooking-bleaching method was applied to obtain tunicate cellulose from Ciona intestinalis [23]. Enzymatic pretreatment was performed to prepare tunicate CNF, which was adjusted to a concentration of $0.5 \% w / w$ in water. The degree of polymerization (DP) of the tunicate CNF was 4200 and the crystallinity index was $94 \%$. The charge density of the tunicate CNF was $43 \mu \mathrm{mol} / \mathrm{g}$, the crystal size was $7.7 \mathrm{~nm}$, and the I $\beta$ ratio was $89.9 \%$ [23]. Commercial starch (water-soluble, $80 \%$ amylopectin and $20 \%$ amylose; Sigma S-9765, Mw: 342.30) was used, without any other treatment.

Kraft lignin samples from both softwood (Norway Spruce, coded as SW) and hardwood (Rose Gum (Eucalyptus grandis), coded as HW) were obtained using the LignoBoost process [24]. The moisture content of the spruce LignoBoost lignin was $6.4 \%$ and that of the eucalyptus LignoBoost lignin was 5.1\%. The ash content of the spruce LignoBoost lignin was $0.6 \%$ and that of the eucalyptus LignoBoost lignin was $1.2 \%$. Another type of softwood lignin obtained by ceramic membrane ultrafiltration was provided by CleanFlow AB (Sweden, coded as CF lignin). The properties of the HW and SW lignin samples, such as the molecular weight, numbers of phenolic and aliphatic hydroxyls, carboxylic acid content, and polydispersity, were previously reported by Tagami et al. [25]. The properties of the CF lignin were reported by Abbadessa et al. [26]. The chemical structure of cellulose is given in Scheme 1a, while lignin represents a more complex and randomly branched polymer that can be characterized by the presence of characteristic main and interlinkage units, as shown in Scheme 1b,c, respectively [27].

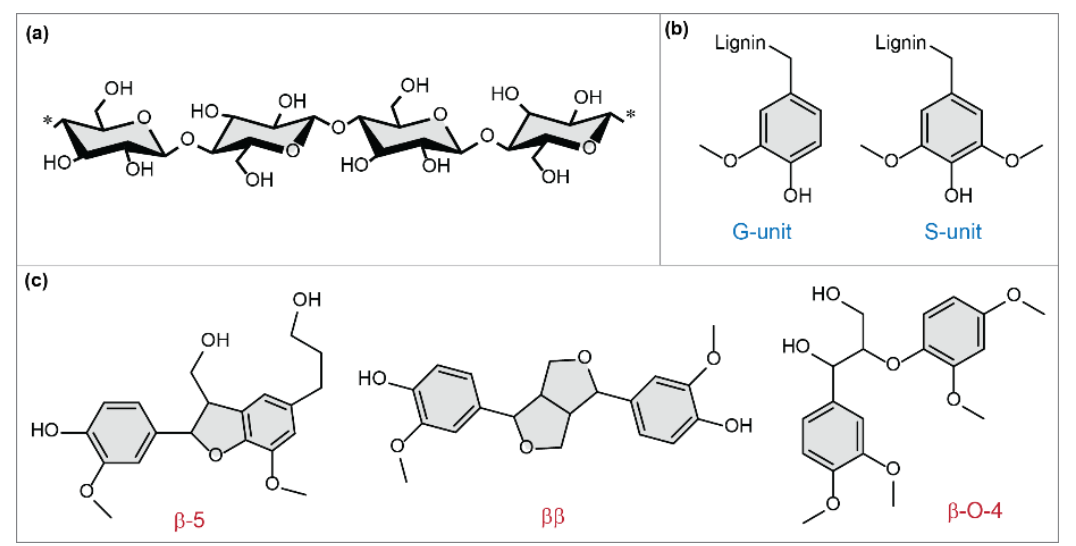

Scheme 1. Chemical structures of the cellulose (a) and most common molecular units present in lignin: (b) main units; (c) main interlinkages [27].

\subsection{Preparation of Lignin-Tunicate CNF-Starch Membranes}

The composite membranes were fabricated by casting a solution of a mixture of lignin, $\mathrm{CNF}$, and starch in high-quality polystyrene Petri dishes with flat, even surfaces. The starch was dissolved in water $(0.5 \mathrm{wt} \%)$ under continuous stirring at $90^{\circ} \mathrm{C}$ to obtain a clear solution, which was cooled to room temperature (sol. 1). Each lignin sample was dissolved in acetone/water $(4: 1, v / v)$ at a concentration of $0.1 \mathrm{wt} . \%(\mathrm{sol} 2)$, then $4 \mathrm{~mL}$ of the $0.5 \mathrm{wt} . \%$ tunicate CNF suspension (sol 3) was blended with $4 \mathrm{~mL}$ of the starch solution and $2 \mathrm{~mL}$ of the lignin solution, mixed well, directly cast into Petri dishes, and dried in a convection oven at $50{ }^{\circ} \mathrm{C}$ overnight to form composite films (referred to as SW/CNF, HW/CNF, and $\mathrm{CF} / \mathrm{CNF}$, depending on the type of lignin used). A blank CNF-starch film (referred to as $\mathrm{CNF}$ ) was made by mixing $4 \mathrm{~mL} C N F$ suspension and $4 \mathrm{~mL}$ starch solution without lignin, followed by casting and drying [23]. To account for the potential variation of membrane thickness, this was measured for each specific sample and test. 


\subsection{Characterization}

The chemical structure of the membranes was analyzed using a scanning FTIR microscope (Nicolet iN10 MX, Thermo Scientific Inc., Waltham, MA, USA) in the range of 4000 to $650 \mathrm{~cm}^{-1}$, with a spectral resolution of $4 \mathrm{~cm}^{-1}$ used in the attenuated total reflectance (ATR) mode with germanium crystal tip. Each spectrum was averaged from 128 scans and spectral data were analyzed using OMNIC software (Thermo Scientific Inc., Waltham, MA, USA). ATR-FTIR allows non-destructive analysis of membrane samples with severalmicron penetration depths. No specific sample preparation was needed, apart from keeping the membrane in a desiccator before the analysis. The pressure was changed accordingly with sample hardness to obtain reliable contact for reproducible spectral acquisitions.

The morphology of the surface of the membrane was observed using a field-emission scanning electron microscope (JSM-7900F, JEOL, Tokyo, Japan). The samples were coated with a thin platinum layer using an ion sputter instrument (Hitachi E-1030, Tokyo, Japan) before the observations. For cross-section preparation, membranes were broken in liquid nitrogen, attached to the holder using a double-sided conductive copper tape, and sputtercoated with $5 \mathrm{~nm}$ of Pt-Pd alloy, before being observed using a field-emission scanning electron microscope (S-4800, Hitachi, Tokyo, Japan). The topographical imaging of the surfaces of the membranes was performed using atomic force microscope (ScanAsyst mode on Bruker Multimode 8 instrument with Nanoscope V controller and E scanner) at room temperature. The membranes were cut into $5 \times 5 \mathrm{~mm}$ pieces and investigated in the air using a Si-doped antimony cantilever (Bruker RFESP-40 probe).

The mechanical properties of the fabricated membranes were assessed on a singlecolumn Instron 5944 tester (Instron Ltd., Norwood, MA, USA) under ambient conditions $\left(21^{\circ} \mathrm{C}, 50 \%\right.$ humidity). A cell with a $500 \mathrm{~N}$ maximum load was used and the pressure of the grips was set to 5 bar. The maximum load was $250 \mathrm{~N}$. The measurements were made on $10 \times 5 \mathrm{~mm}$ strips. The thickness of each sample was used for the strain calculations. The test was performed on 3 specimens of each lignin-containing sample and once on the reference CNF sample.

The specific surface area and pore size were determined from nitrogen adsorptiondesorption isotherms at $77 \mathrm{~K}$ (Micromeritics ASAP 2020 sorption analyzer) of samples that had been degassed at $353 \mathrm{~K}$ before the measurements. The pore size distribution (PSD) was calculated using the Barret-Joyner-Halenda (BJH) method.

Thermogravimetric analysis (TGA) was carried out on a TGA/DSC-1 instrument (Mettler Toledo, Columbus, OH, USA) with a heating rate of $10^{\circ} \mathrm{C} \mathrm{min}^{-1}$, an air flow of $50 \mathrm{~mL} \mathrm{~min}{ }^{-1}$, and a temperature range of $30-600{ }^{\circ} \mathrm{C}$.

Differential scanning calorimetry (DSC) was performed using a Netzsch instrument (DSC $204 \mathrm{~F} 1$ Phoenix ${ }^{\circledR}$, Selb, Germany) under a nitrogen atmosphere (flow rate $50 \mathrm{~mL} \mathrm{~min}^{-1}$ ). The samples weighing 5-6 mg were enclosed in aluminum crucibles and heated from room temperature to well above the glass transition point $\left(\mathrm{T}_{\mathrm{g}}\right)$ at $10{ }^{\circ} \mathrm{C} \mathrm{min}^{-1}$, with an empty crucible used as the reference. The $T_{g}$ value was determined in the second heating run as the midpoint of the onset and the end of a step transition using the Netzsch analysis software (Proteus Analysis). The $\mathrm{T}_{\mathrm{g}}$ values of the lignins were determined using a MettlerToledo DSC 820 instrument (Columbus, OH, USA), with the samples being heated in a $100 \mu \mathrm{L} \mathrm{Al}$ crucible at $10^{\circ} \mathrm{C} / \mathrm{min}$, with a $\mathrm{N}_{2}$ gas flow of $50 \mathrm{~mL} \mathrm{~min}^{-1}$ up to $220^{\circ} \mathrm{C}$. The $\mathrm{T}_{\mathrm{g}}$ value was determined in the second heating run as the midpoint value between the onset and the end of a step transition

For the single-gas permeability measurements, membranes were masked with a metal gasket to provide a circular open area with a diameter of approximately $1 \mathrm{~cm}$, which was stuck to the surface of the membrane using a 5-min two-component epoxy glue (Devcon \#14250). The active area of the membrane was precisely measured using image analysis software (ImageJ). The permeation rates of dry gases $\left(\mathrm{H}_{2}, \mathrm{O}_{2}, \mathrm{~N}_{2}, \mathrm{CO}_{2}\right)$ through the membranes were measured at $25{ }^{\circ} \mathrm{C}$ using the GTR-31A gas barrier testing system (GTR Tec Corp., Japan), in a cell shown schematically in Figure 1. The permeability (P) of the gases in barrer units $\left(1\right.$ barrer $\left.=10^{-10} \mathrm{~cm}^{3}(\mathrm{STP}) \mathrm{cm} \mathrm{cm}^{-2} \mathrm{~s}^{-1} \mathrm{cmHg}^{-1}\right)$ was estimated 
for each membrane. The ideal selectivity between two different gases of the composite membrane was calculated as the ratio, $\alpha(\mathrm{A} / \mathrm{B})=\mathrm{P}_{\mathrm{A}} / \mathrm{P}_{\mathrm{B}}$, where $\mathrm{P}_{\mathrm{A}}$ and $\mathrm{P}_{\mathrm{B}}$ are the respective permeabilities of gases $A$ and $B$, respectively.

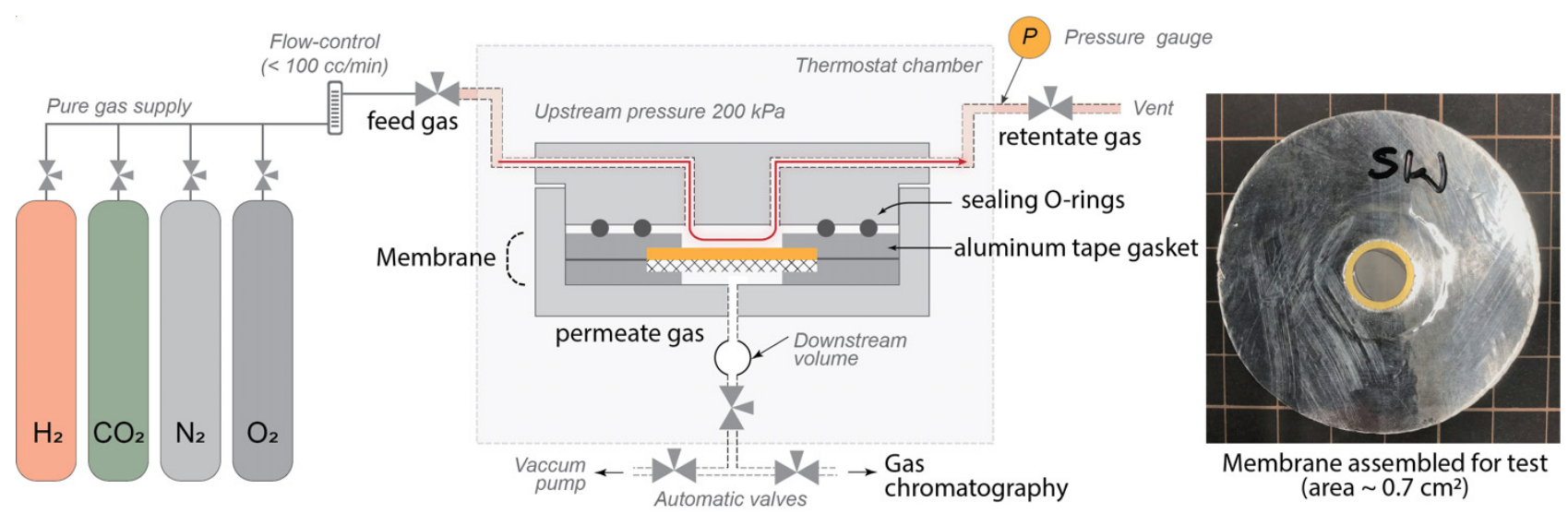

Figure 1. Schematic illustration of the gas permeability measurement setup. Photography shows the membrane prepared for the gas permeability testing — the small membrane area in the middle is exposed to the compressed gas in the GTR31A system.

\section{Results and Discussion}

For example, for gas permeability tests, circles measuring $1 \mathrm{~cm}$ in diameter were used and the thickness was measured in the precise center of each studied sample. The variability in measured thickness values was not large and changes within several $\%$ are considered negligible. Photographs of the nanocellulose membrane with and without different types of lignin are shown in Figure 2. After complete drying of the cast solutions, blank CNF membranes were naturally detached from the polystyrene surface without forceful peeling, whereas samples containing lignin (SW/CNF, HW/CNF, and CF/CNF) were more brittle and could not be easily peeled off. This likely originated from the hydrophobic interaction between lignin and polystyrene both having benzene rings in their structure, which may promote stronger adhesion. To release the membranes, ethanol was added to the Petri dishes, which enabled the membranes to be detached as self-supporting films. The 25-mm-diameter samples shown in Figure 2 were cut using a manual punch (Dumbbell Co. Ltd., Saitama-Ken, Japan).

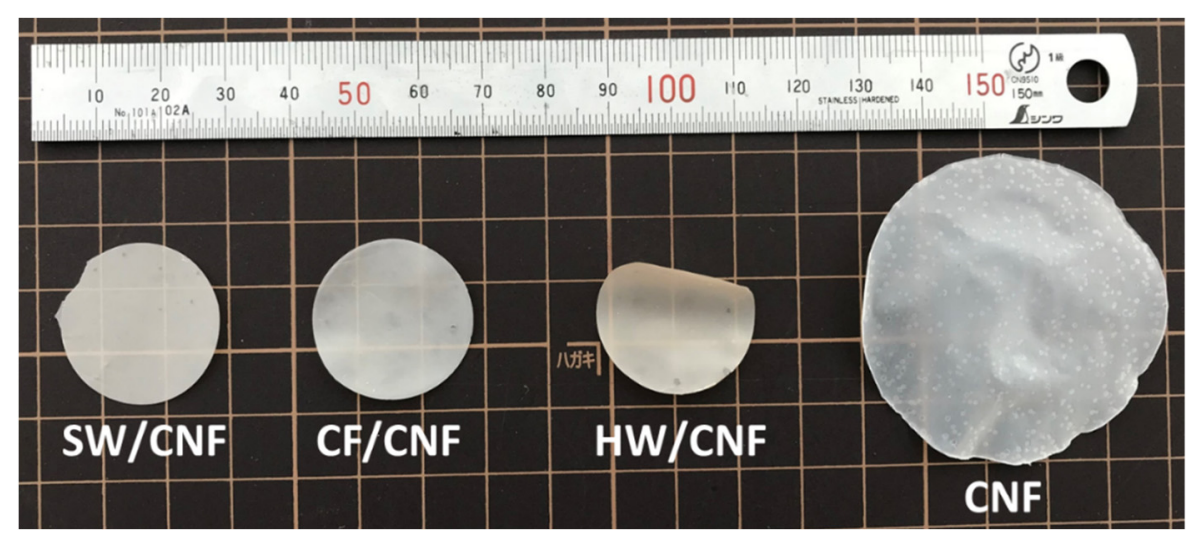

Figure 2. Photograph of the membranes. The lignin-containing samples were more rigid and better attached to the polystyrene dishes used for casting. Only circles $2.5 \mathrm{~cm}$ in diameter were recovered, while CNF was completely self-detached from the substrate after drying.

The membrane surfaces were first investigated using SEM and were found to be uniform, as shown in Figure 3. Observation at higher magnifications revealed that the 
surfaces of all the membranes were porous, presumably because the high crystallinity of the CNF prevented dense packing of the fibers despite the presence of starch, which was probably uniformly stacked on the fiber surfaces due to the similarity in the chemical structures of these carbohydrates. The addition of lignin into the nanostructure mixed with cellulose nanofibers is believed to modify the porous structure of the nanocellulose with characteristic pores below 10 nanometers. In the case of the SW/CNF membrane (Figure 3, second row), lignin is visible in the form of nanoparticles uniformly mixed with the cellulose nanofibers, whereas in the $\mathrm{CF} / \mathrm{CNF}$ sample, densification of the surface is apparent (Figure 3, bottom row).
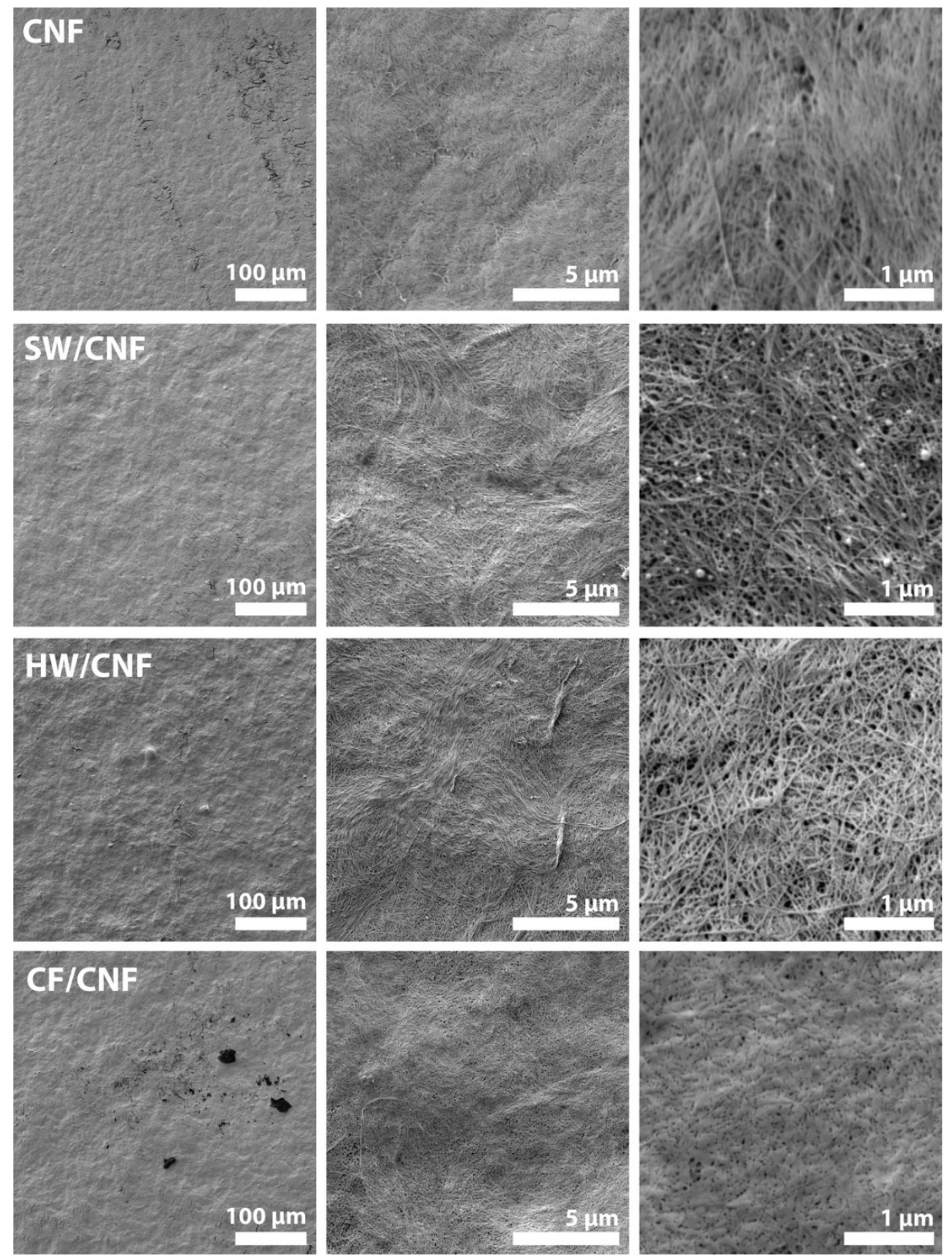

Figure 3. SEM images of surfaces of composite membranes at different magnifications (row 1: CNF, row 2: SW/CNF, row 3: $\mathrm{HW} / \mathrm{CNF}$, row 4: $\mathrm{CF} / \mathrm{CNF}$ ).

To gain better insight into the surface morphology atomic force microscopy (AFM) was used to investigate the topography of the CNF and lignin-containing CNF membranes 
(Figure 4). The CNF membrane surface was covered by entangled cellulose nanofibrils with a diameter of $27 \pm 4 \mathrm{~nm}$. For the lignin-containing membranes, quasi-spherical particles were observed additionally to fibers, which can be attributed to lignin aggregates, and according to the size, to lignin nanoparticles. The largest nanoparticles were observed on the surfaces of SW/CNF membranes, followed by CF/CNF and HW/CNF membranes. The larger nanoparticle size of the SW/CNF membrane can be explained by the higher energy of the interactions between G-units in the structure of softwood lignin than that between S-units [28]. This observation is in line with our previous work, which focused on the formation of lignin nanoparticles, where larger particles for softwood lignin than hardwood lignin were observed [29].
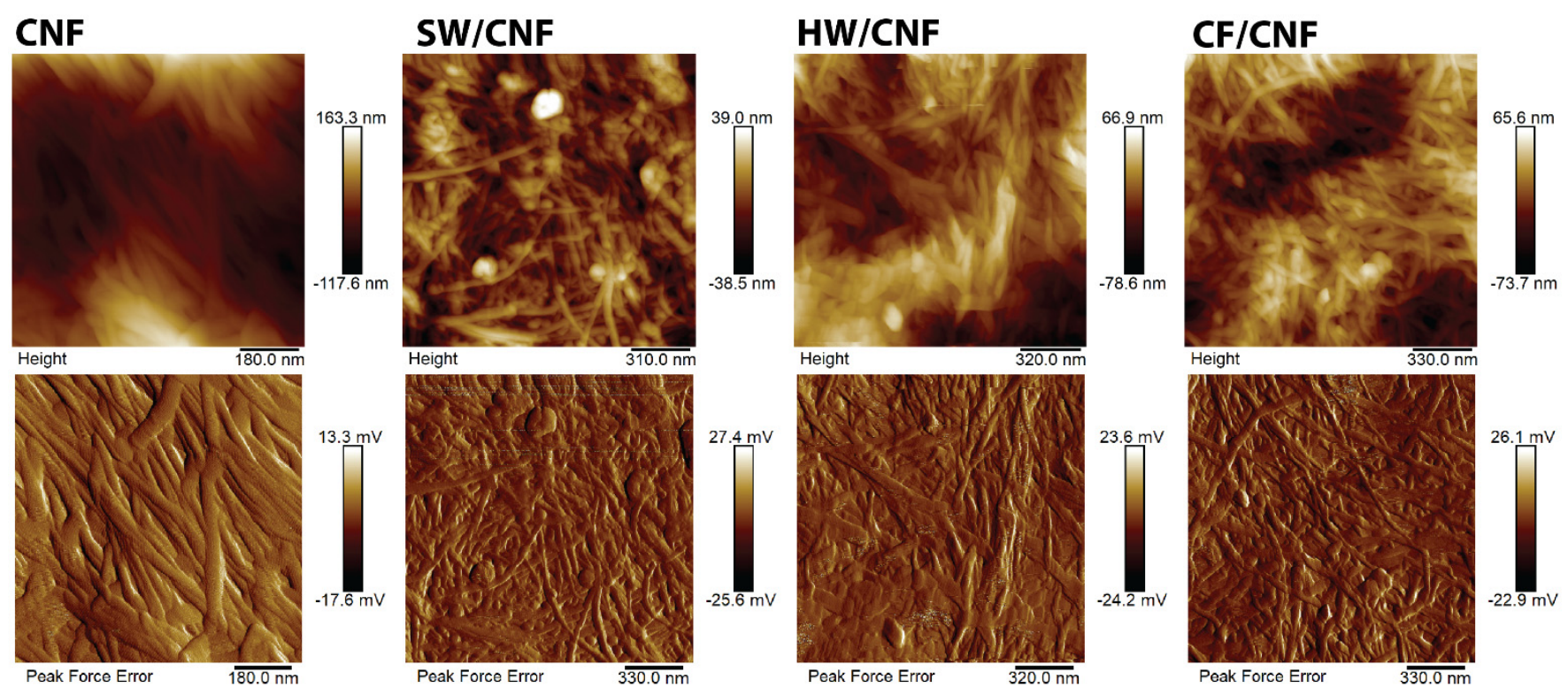

Figure 4. AFM images of the surface of composite lignocellulose membranes: height sensor (top row) and peak force error (bottom row) images.

The cross-sections of the membranes were also studied, and the results are shown in Figure 5. The thicknesses of the membranes were in the range of 20-30 $\mu \mathrm{m}$. Lignin cannot be distinguished in these images. The SEM images show elongated and intertwined CNF fibrils forming a quasi-layered structure. The simple CNF membrane is packed more densely and more uniformly than the other membranes. The membranes containing softwood lignin (SW/CNF and $\mathrm{CF} / \mathrm{CNF}$ ) have similar surface morphologies, however the $\mathrm{HW} / \mathrm{CNF}$ membrane surface has a more rough and wavy structure. These characteristic features may be due to electrostatic repulsion between the lignin and cellulose, both of which have a weak, negatively charged surface [30,31]. The morphological differences can also be explained by differences in the energy of interaction in the lignin units (shown in Figure 1). Namely, the main linkages are $\beta-\mathrm{O}-4^{\prime}$ substructures, $\beta-5$ phenyl coumaran structures, and $\beta-\beta^{\prime}$ resinol substructures, while the energy of the non-covalent $\pi-\pi$ interactions between G-units is higher than that between S-units [28]. This is expected to result in a stronger bonding between softwood lignin molecules (SW and CF) than between hardwood lignin molecules (HW), leading to a denser packing of lignin in the membrane. 

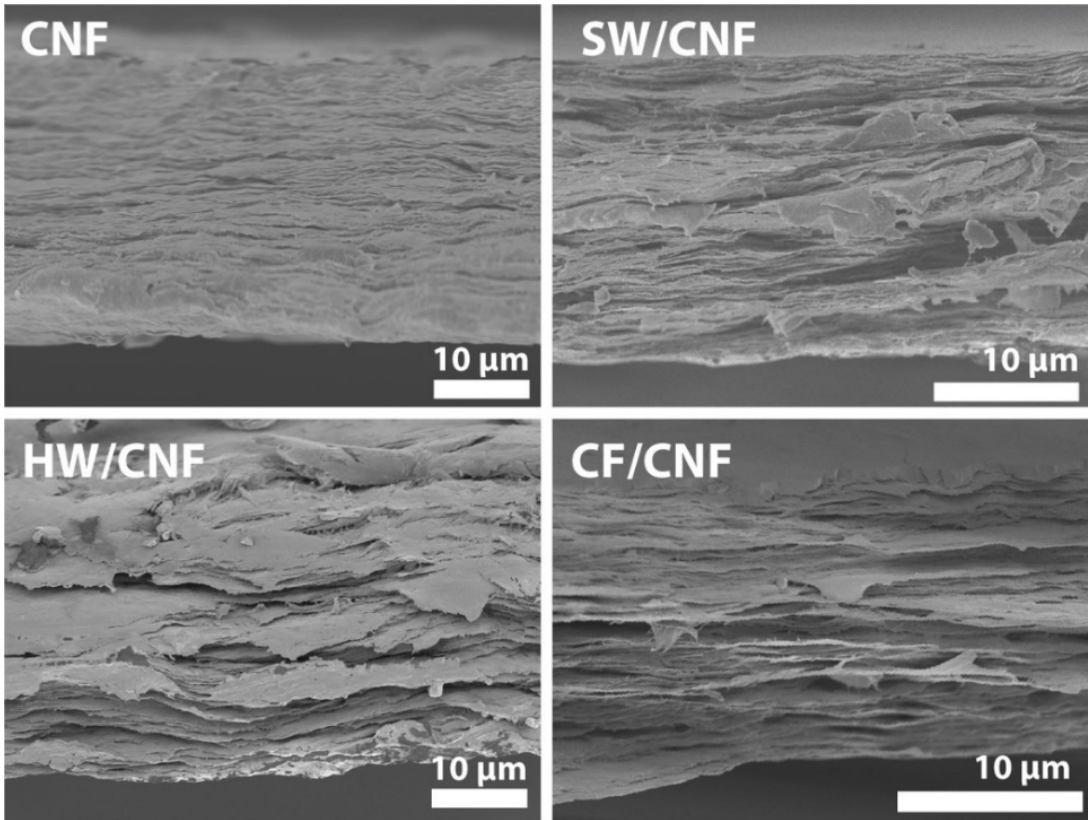

Figure 5. Cross-sectional SEM images of composite lignocellulose membranes.

Infrared spectra acquired in the attenuated total reflection mode are shown in Figure 6. The membranes demonstrated similar chemical structures, since they have CNF and starch as the common dominant components ( 95\%). Adsorption bands around $3300 \mathrm{~cm}^{-1}$ and $2900 \mathrm{~cm}^{-1}$ can be attributed to the O-H and C-H stretching vibrations, respectively, in the cellulose polymer and starch [32]. They appear as a superposition of sharper bands of highly crystalline nanocellulose with the broad peaks of amorphous starch [33]. The series of peaks in the 1000-1250 $\mathrm{cm}^{-1}$ range with the most intense at $1057 \mathrm{~cm}^{-1}$ and $1034 \mathrm{~cm}^{-1}$ can be attributed to C-O-C vibrations of cellulose pyranose rings. Bands at $1427 \mathrm{~cm}^{-1}$ and $1315 \mathrm{~cm}^{-1}$ are attributed to the deformation of $\mathrm{OH}$ and $\mathrm{CH}_{2}$ bonds, respectively, while the broad peak at $1643 \mathrm{~cm}^{-1}$ originates from the water adsorbed in the membranes [33]. No absorption bands related to lignin structures are distinguishable in the FTIR spectra due to the low content of lignin in the membranes and the peculiarity of its distribution in the membranes, as demonstrated by AFM.

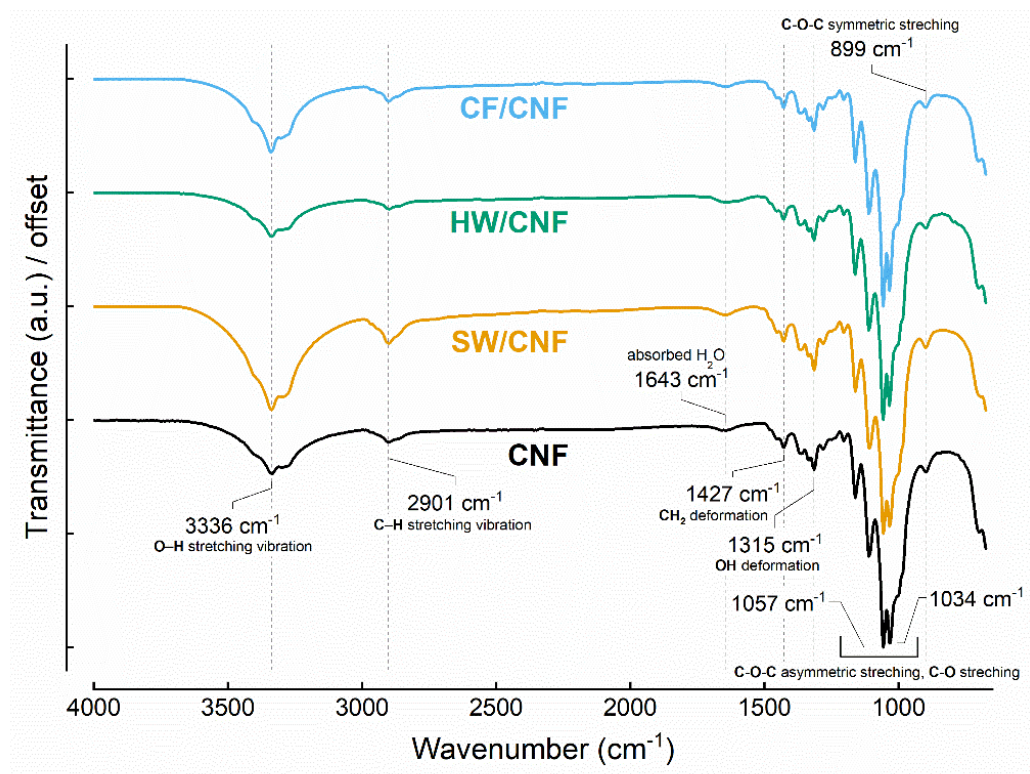

Figure 6. Attenuated total reflection-FTIR spectra of the lignocellulose membranes. 
The mechanical properties were assessed via a tensile test and the results are presented in Figure 7 and Table 1. The addition of $\sim 5 \%$ of lignin had a considerable effect on the properties of the membranes, with a ca. two-fold increase in modulus of elasticity from 3.7 to $\sim 6 \mathrm{Gpa}$ and a decrease in the strain at break from ca. $4 \%$ to ca. $2 \%$ The HW/CNF had the highest modulus and the lowest strain at break The properties of $\mathrm{SW} / \mathrm{CNF}$ and CF/CNF were similar to each other. Overall, the mechanical tests showed that the lignin acted as a reinforcing component, in line with the results reported in a previous study [23]. The increased modulus is a desired property for the membrane systems in order to achieve better mechanical stability, however flexibility is also usually required, as the membranes need to withstand handling before immobilization in larger module assemblies. For practical applications, the mechanical properties should also be assessed in varying environmental conditions (e.g., various humidity levels).
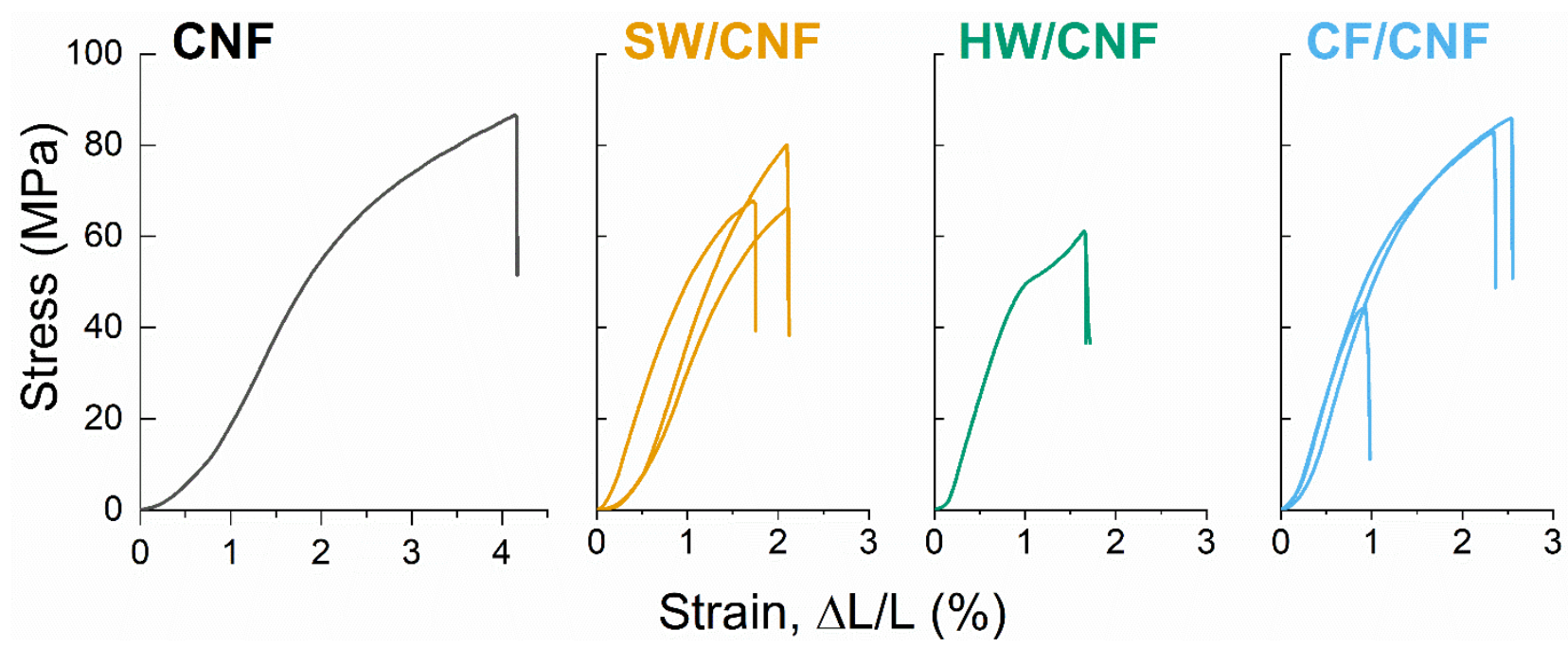

Figure 7. Stress-strain curves for the fabricated lignocellulose membranes.

Table 1. Mechanical properties of the fabricated films.

\begin{tabular}{cccc}
\hline Sample & Modulus (MPa) ${ }^{\mathbf{a}}$ & $\begin{array}{c}\text { Tensile Strain at } \\
\text { Break (\%) }\end{array}$ & $\begin{array}{c}\text { Tensile Stress at Break } \\
(\mathbf{M P a})^{\mathbf{a}}\end{array}$ \\
\hline CNF & 3771 & 4.1 & 86 \\
SW/CNF & $5670 \pm 530$ & $1.98 \pm 0.217$ & $71.3 \pm 7.6$ \\
HW/CNF & $6785 \pm 6$ & $1.65 \pm 0.001$ & $61.2 \pm 0.0$ \\
CF/CNF & $6677 \pm 175$ & $2.45 \pm 0.142$ & $84.4 \pm 2.0$ \\
\hline
\end{tabular}

Note: ${ }^{\mathrm{a}}$ average value $\pm \mathrm{SD}$, excluding outliers.

The thermal properties of the CNF membranes were assessed using thermogravimetric analysis. As shown in Figure 8a, all of the membranes demonstrated excellent thermal stability up to $300{ }^{\circ} \mathrm{C}$, when degradation started. The weight loss for the CNF membrane between 300 and $400{ }^{\circ} \mathrm{C}$ was $62.2 \%$, however for the SW/CNF, HW/CNF, and $\mathrm{CF} / \mathrm{CNF}$ composites the values were $72.4 \%, 76.3 \%$, and $72.3 \%$, respectively. This increase in mass loss was probably due to the decomposition of lignin. According to the differential thermogravimetry (DTG), the pure cellulose membrane had a peak at $351{ }^{\circ} \mathrm{C}$, whereas the lignin-containing membranes had peaks at $359^{\circ} \mathrm{C}$. The fact that the decomposition starts at a higher temperature suggests that the addition of lignin leads to a modest improvement in thermal stability. 

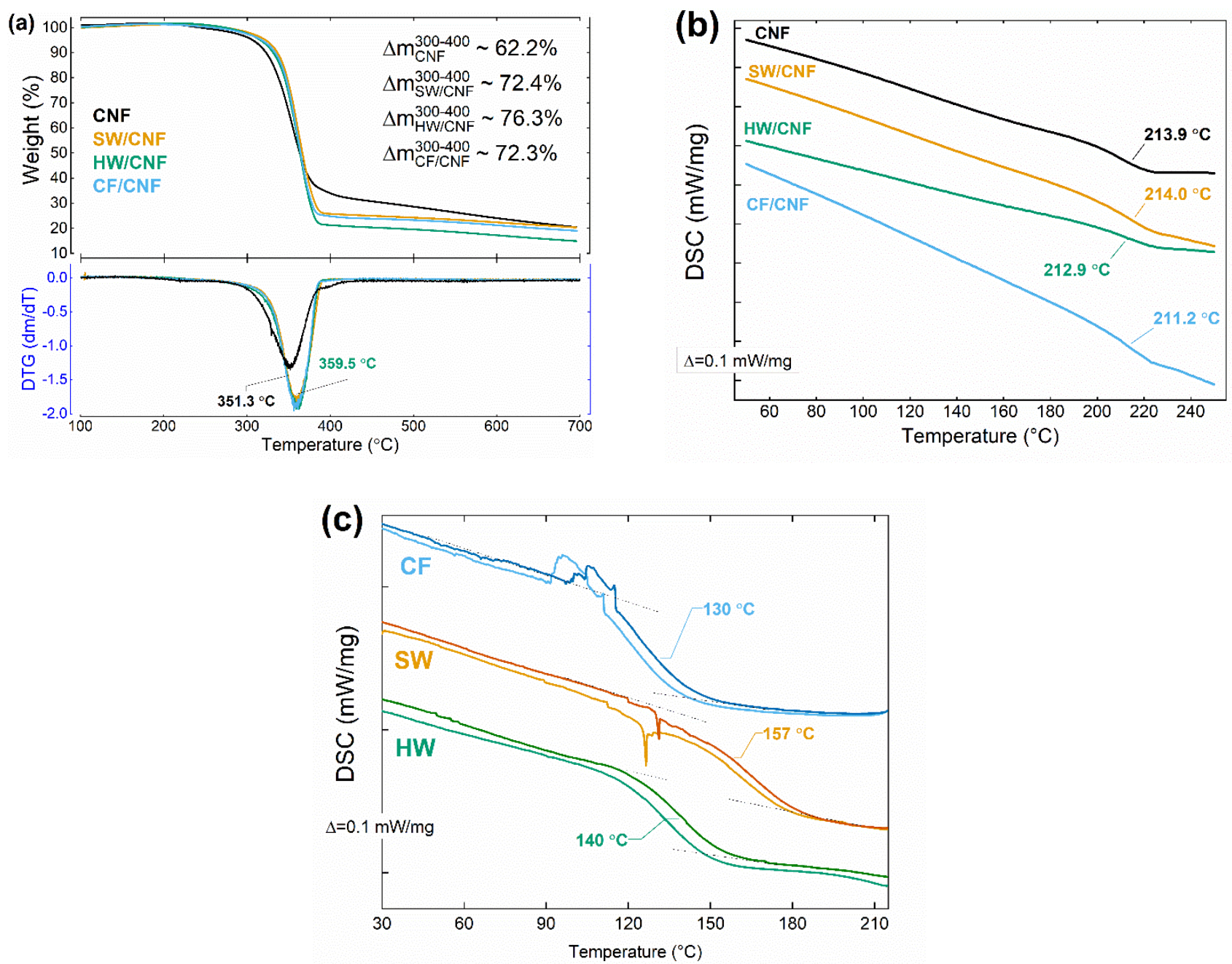

Figure 8. (a) Thermogravimetric analysis and (b) dynamic scanning calorimetry analysis of the nanocellulose-lignin membranes. (c) Dynamic scanning calorimetry analysis of the lignins.

The glassy state of the composites was analyzed using dynamic scanning calorimetry (DSC). In Figure 8b, all of the samples show a step-like change in the curve at around $214{ }^{\circ} \mathrm{C}$, indicating that this is the glass transition temperature $\left(\mathrm{T}_{\mathrm{g}}\right)$ and that the presence of lignin did not influence this transition. The glass transition is apparently driven by the CNF. The thermal properties of the different lignins are shown in Figure 8c. All of the lignin samples had significantly lower $\mathrm{T}_{\mathrm{g}}$ values than those of the composites with CNF $\left(130-160{ }^{\circ} \mathrm{C}\right)$, in agreement with the literature $[34,35]$. The fact that the $\mathrm{T}_{\mathrm{g}}$ of lignin was not detected in the DSC scans of the composites suggests that it was present in a highly dispersed state, in contrast to its existence as a continuous phase in plant cell secondary walls [14].

Microscopic investigation of the membranes suggested that they are porous. To verify this quantitatively, nitrogen adsorption-desorption isotherms were acquired for the nanocellulose and lignin-modified materials. The results are provided in Figure 9a-all samples manifested the characteristic type IV isotherms with hysteresis loops with an H2 shape [36,37]. This type of loop is a characteristic feature of mesoporous materials, and it can be also interpreted by percolation effects in highly heterogeneous pore networks [36]. The BET surface area was $4.9 \mathrm{~m}^{2} \cdot \mathrm{g}^{-1}$ for the CNF membrane and $34.7 \mathrm{or} 43.7 \mathrm{~m}^{2} \cdot \mathrm{g}^{-1}$ with the addition of softwood or hardwood lignin, respectively. The largest specific surface area $\left(53.0 \mathrm{~m}^{2} \cdot \mathrm{g}^{-1}\right)$ was found for the cellulose membrane with added membrane-filtered $\mathrm{CF}$ lignin, indicating that the distribution was more uniform. The total pore volume was found to be $0.089-0.132 \mathrm{~cm}^{3} \cdot \mathrm{g}^{-1}$ for the lignin-containing membranes and $0.009 \mathrm{~cm}^{3} \cdot \mathrm{g}^{-1}$ 
for the CNF. The pore-size distribution curves in Figure $9 b, c$ were obtained using the BarretJoyner-Halenda (BJH) method [38]. According to the IUPAC classification [37], all of the synthesized composites were mesoporous materials with pore diameters ranging between 2 and $12 \mathrm{~nm}$ according to the desorption branch and between 2 and $40 \mathrm{~nm}$ according to the adsorption branch. The characteristics of the materials are summarized in Table 2.
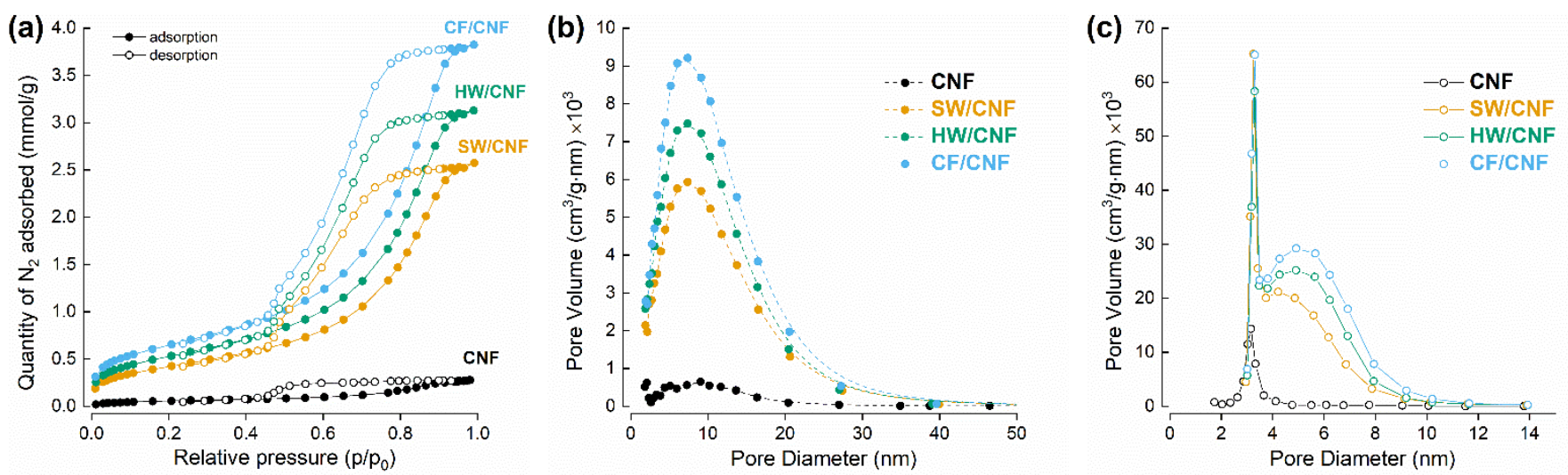

Figure 9. (a) Nitrogen adsorption-desorption isotherms and pore-size distribution curves calculated using the BarretJoyner-Halenda (BJH) method for the (b) adsorption and (c) desorption branches of the isotherms.

Table 2. Textural characteristics of materials.

\begin{tabular}{ccccc}
\hline Sample & $S_{\text {BET }}, \mathbf{~ m}^{\mathbf{2}} \mathbf{g}$ & $V_{\text {pores }}, \mathbf{c m}^{\mathbf{3}} / \mathbf{g}$ & $D_{\text {pores }}(\mathbf{a d s}), \mathbf{n m}$ & $D_{\text {pores }}(\mathbf{d e s}), \mathbf{n m}$ \\
\hline CNF & $4.96 \pm 0.14$ & 0.009 & 8.1 & 3.3 \\
SW/CNF & $34.7 \pm 0.16$ & 0.089 & 8.3 & 4.6 \\
HW/CNF & $43.7 \pm 0.27$ & 0.108 & 8.0 & 4.9 \\
CF $/$ CNF & $53.0 \pm 0.22$ & 0.132 & 8.1 & 5.0 \\
\hline
\end{tabular}

Note: $S_{\mathrm{BET}}$ 一the Brunauer-Emmet-Teller (BET) surface area; $V_{\text {pores }}$-total pore volume; $D_{\text {pores }}$ - $\mathrm{BJH}$ average pore diameter calculated from adsorption and desorption branches of isotherms.

The main purpose of this study was to examine the gas transport through the abovedescribed completely bio-based composite membranes. Pure gas permeation was assessed using the differential pressure method. Figure 10 shows the resulting permeabilities for four different gas species through the fabricated membranes. The permeability of hydrogen is greater in all membranes than that of larger molecules. Usually, the permeability of gases through the dense polymeric membranes is described by the solution-diffusion mechanism, while the permeability can be decoupled into the solubility of the gas in the membrane materials and diffusivity. The permeability coefficient can be expressed as a product of solubility and diffusivity coefficients [39]. However, in cases where the membranes are porous, the solubility in and diffusion of gas through the material itself are negligibly small compared to gas transport through the pores. When the pore sizes of a membrane are $0.1 \mu \mathrm{m}$ or larger, gas permeation takes place by convective flow, as described by Poiseuille's law [40]. If the pore radius $r$ is much larger than the kinetic diameter of the gas but smaller than the mean free path $(\lambda)$ of the gas, diffusing gas molecules undergo more collisions with the pore walls rather than with other gas molecules. Gas diffusion in this region is called Knudsen diffusion. On collision with the pore walls, the gas molecules are momentarily adsorbed and then reflected in a random direction. Molecule-molecule collisions are rare, meaning that each gas molecule moves independently of the others. With gas mixtures in which the different species move at different average velocities, separation is possible [40]. In the case of our membranes, if the pores of the membranes were larger, the gases would diffuse at approximately similar rates, without selectivity to certain gas species. Although the selectivities were similar for all the membranes (Figure 10b), the transport rates were very different (Figure 10a). Specifically, the SW/CNF membrane 
had permeabilities two orders of magnitude higher than those of CNF and three orders higher than those of HW/CNF. Such differences can be explained by the greater porosity, however the adsorption tests showed that it was higher in all of the lignin-containing membranes. The fact that the selectivity was similar in all cases is indirect evidence that all samples had similar pore geometries. Therefore, we suggest that differences in the observed permeabilities were caused by the lignin distribution. Different gas permeabilities correspond well to membrane morphology observations using SEM and AFM; namely, the lignin distributions are different in all samples, ultimately present in the form of larger quasi-spherical particles in SW/CNF, expanding the rigid CNF fiber network. The transport mechanism in the SW/CNF membrane is closest to Knudsen diffusion (orange circles on the selectivity plot close to the Knudsen grey bars), which can be explained by the differences in molecular weights of different gas species ( $\mathrm{x}$-axis in Figure 10b).
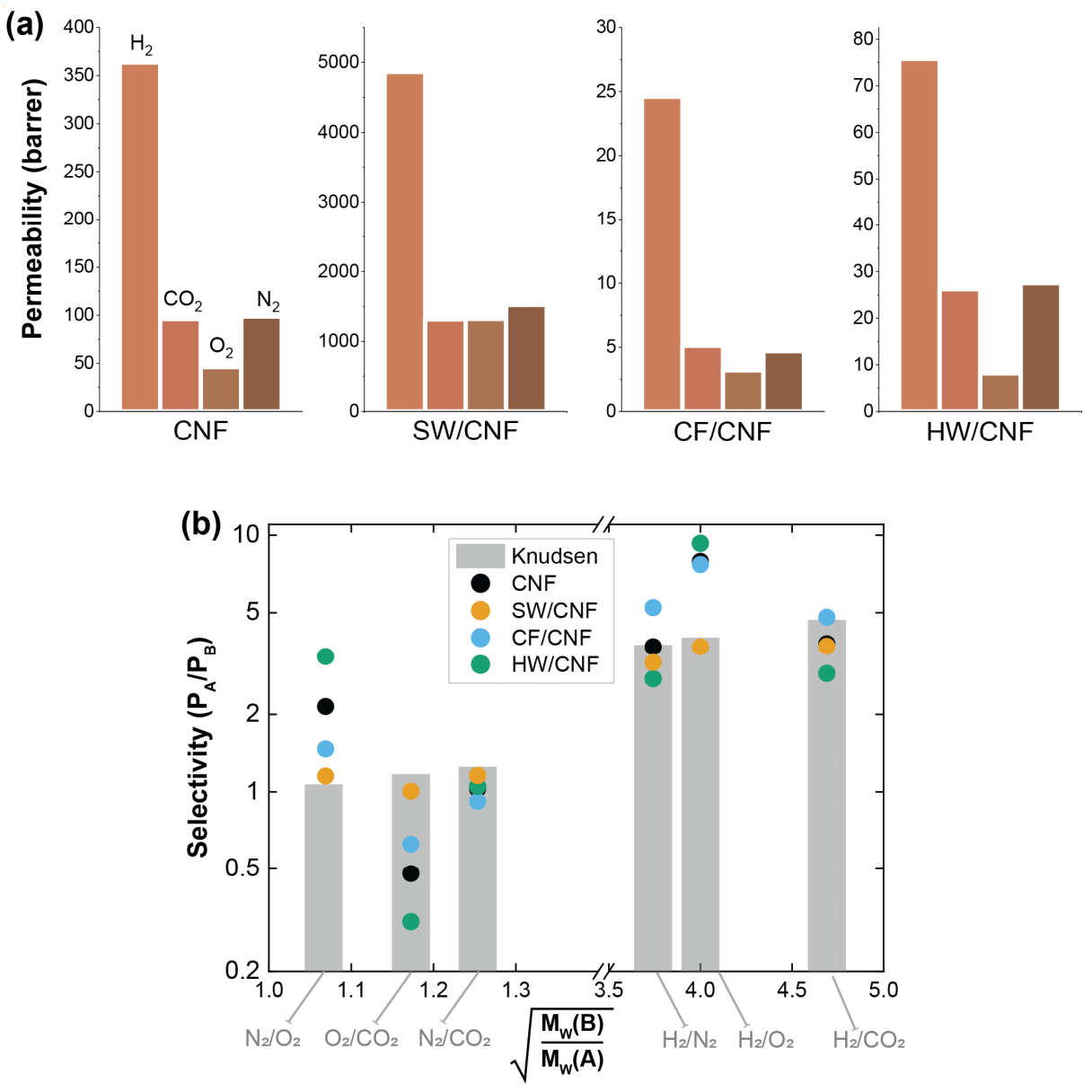

Figure 10. (a) Gas permeability through the membranes. (b) Selectivity of gas transport in fabricated membranes compared to the Knudsen diffusion model (grey bold line).

We can suggest that the variation in gas permeabilities was strongly influenced not only by the amount but also by the distribution of the lignin in the composites. The suggested difference is shown schematically in Figure 11. The chemical nature of the lignin determines how it interacts with the cellulose-starch matrix, expanding the CNF network with SW/CNF or creating a micromorphology impeding the gas transport in CF/CNF. Taking into account the morphology and porosity of the membranes, the gas permeation should be considered as a geometrical rather than a chemical problem. This has been very well studied in the literature; however, gas flow description is rather complex [41,42]. A recent numerical simulation study of permeability in fibrous-particle structures with the application of fractal models showed that permeability is expected to increase with an increase of particle diameter [42]. This outcome corresponds to the observed results of the 
SW/CNF membrane, in which SW lignin is indeed present in the form of quasi-spherical particles. In cases where lignin takes up more random shapes, the numerical description would be even more complex.

(a)

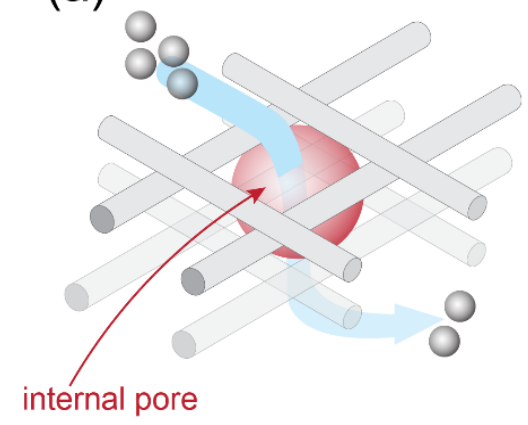

(b)

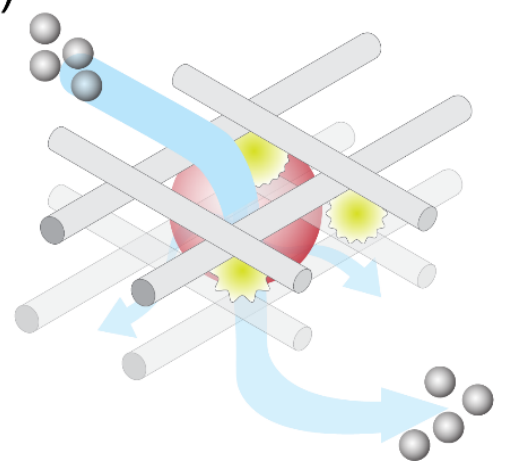

(c)

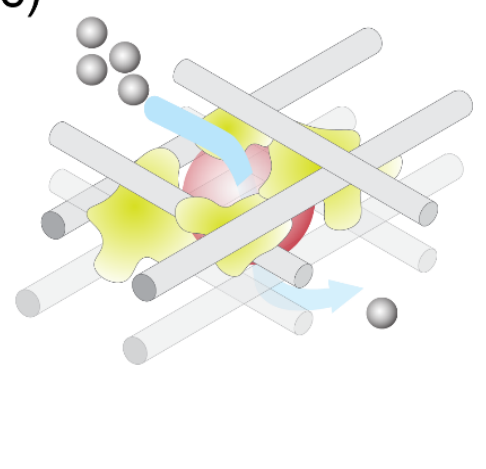

Figure 11. Distribution of lignin inside the CNF matrix, which could explain the observed porosity and gas permeability data (a) for the blank CNF-starch network. (b) CNF network expanded with weakly interacting lignin particles (yellow; SW/CNF). (c) CNF network with strongly interacting lignin molecules covering the fibers and able to disrupt the percolated pathways needed for gas transport but not changing the overall pore structure.

The important result of the gas transport study is that the fabricated membranes fit into the intermediary range of porosity between dense membranes (where gas can be separated via size-sieving or solution-diffusion mechanism) and ordinary Poiseuille lawgoverned flow membranes (non-selective). The achieved selectivities of such membranes are, however, too low for any practical gas separation applications. However, the result is relevant because there is a strong interest in utilizing widely available biopolymers such as cellulose and lignin in a variety of applications. In respect to gas permeability, nanocellulose is often mentioned as a good gas barrier material, and therefore is suggested to be used for sustainable packaging or other applications $[1,3,10-12,43-45]$. The results of our work show that this cannot be a default assumption, as the gas barrier will strongly depend on the material micromorphology and crystallinity. To put the results of the obtained permeabilities into context, they are compared with several reports from the literature in the Table A1 of the Appendix A. The gas permeabilities in the presented membranes were much larger compared to dense membranes. While some studies reported highly selective gas transport through nanocellulose-based membranes [10,44], the permeabilities of dry membranes are usually extremely low, making such membranes impractical for gas separation. In this respect, we reported nanocellulose membranes to demonstrate trade-off phenomena between selectivity and permeability [46]. At the same time, other uses of nanocellulose were found for the microfiltration of nanoparticles (significantly bigger than gas molecules) [13]. Gas transport in the membranes presented in this work fitted roughly in between these two extreme cases, and although some selectivity was observed due to the Knudsen mechanism, this is not practical for the actual gas separation applications. As the studies of gas permeability in nanocellulose-based membranes are still scarce, we believe that this work will indicate to other researchers that when highly crystalline nanocellulose fibers are used, they are unlikely to create the dense structure usually needed to achieve practical differences in gas transport rates, and as a result the good separation ability. However, these types of highly crystalline mechanically strong fibers with the addition of lignin can be used as reinforcing elements in various composites.

\section{Conclusions}

The current study presented an initial investigation of gas transport along with a thorough characterization of a new class of completely bio-based membranes composed of tunicate nanocellulose, starch, and wood-derived lignin. The composites that can be 
referred to as "artificial wood" recombine the structures of materials commonly found in higher plants but having different, non-plant-based origins. The addition of $5 \%$ lignin to CNF membranes led to significant changes in the properties, depending on the chemical structure, botanical origin, and polydispersity of the lignin. The improved mechanical strength of membranes containing lignins was shown by the higher elastic modulus of 6 GPa in lignin-containing membranes compared to $\sim 3$ GPa in blank CNF. The porosity of the membranes and specific surface areas studied using nitrogen adsorption increased in all samples containing lignin, however no significant differences were observed in pore geometries. Microscopy studies (using SEM and AFM) showed that lignins are present in the membranes in the form of dispersed nanoparticles.

The investigation of the gas permeabilities through the CNF and CNF-lignin membranes surprisingly showed very different gas permeabilities (e.g., $\mathrm{CO}_{2}$ permeability values of 1315,26 , and 5 barrers in lignin-CNF composites vs. 96 barrers in blank CNF). This suggests the importance of molecular interactions between lignin and cellulose and the resulting composite structure morphology, which can provide higher or lower permeabilities depending on the composition. Gas selectivities indicate a Knudsen mechanism of permeation in all membranes, with larger selectivity for hydrogen as the gas with the smallest kinetic diameter.

This study highlights that in the engineered membranes, the morphologies and properties will strongly depend on the components, and therefore may bring the level of control needed for environmentally friendly materials completely made of natural sources. However, future studies should be focused on lignin-cellulose combinations forming denser structures or ultramicroporous membranes, which are expected to result in higher selectivity towards important gas separations.

Author Contributions: Conceptualization, I.P. and R.S.; methodology, R.S.; formal analysis, I.P. and R.S.; investigation, I.P., R.S., and T.B.; resources, Y.Z., M.L., S.F., and O.S.; data curation, R.S.; writingoriginal draft preparation, I.P. and R.S.; writing - review and editing, I.P. and R.S.; visualization, R.S.; funding acquisition, I.P., R.S., S.F., and O.S. All authors have read and agreed to the published version of the manuscript.

Funding: This work was supported by the World Premier International Research Center Initiative (WPI), sponsored by the Japanese Ministry of Education, Culture, Sports, Science, and Technology (JSPS); and Moonshot Research and Development Program (JPNP18016), commissioned by the New Energy and Industrial Technology Development Organization (NEDO). R.S. acknowledges the Japan Society for Promotion of Science (JSPS) for a Grant-in-Aid for Early Career Scientists (JSPS KAKENHI Grant Number JP19K15342). I.P. acknowledges the Wood and Pulping Chemistry Research Network (WPCRN) for financial support for his work.

Acknowledgments: The authors highly appreciate the help of Anthony Bristow (Bristow Consulting \& Språktjänst) for English corrections and comments on this work. Ie. Pylypchuk would like to thank Tobias Benselfelt (KTH-Royal institute of technology) for his help with the AFM instrument. R. Selyanchyn acknowledges the MIRAI program (mirai.nu), which aims to promote collaborative research between Swedish and Japanese universities.

Conflicts of Interest: The authors declare no conflict of interest. The funders had no role in the design of the study; in the collection, analyses, or interpretation of data; in the writing of the manuscript, or in the decision to publish the results. 


\section{Appendix A}

Table A1. Comparison of the gas permeability values of the developed lignin-CNF membranes with examples from the literature.

\begin{tabular}{|c|c|c|c|c|c|c|c|c|}
\hline \multirow{2}{*}{ Membrane Description } & \multirow{2}{*}{ Preparation Method } & \multirow{2}{*}{$\begin{array}{l}\text { Thickness, } \\
\mu \mathrm{m}\end{array}$} & \multirow{2}{*}{$\begin{array}{c}\text { Gas Permeability } \\
\text { Test }\end{array}$} & \multicolumn{4}{|c|}{ Permeability, Barrer ( \pm SD Where Available) } & \multirow{2}{*}{ Ref. } \\
\hline & & & & $\mathrm{CO}_{2}$ & $\mathbf{N}_{2}$ & $\mathrm{O}_{2}$ & $\mathrm{H}_{2}$ & \\
\hline $\begin{array}{l}\text { Cellulose whiskers }(\mathrm{W}) \text { from } \\
\text { native sisal fibers }\end{array}$ & \multirow{2}{*}{$\begin{array}{l}\text { casting aqueous solutions } \\
\text { in Teflon molds, } \\
\text { evaporation at } 25^{\circ} \mathrm{C}, 5 \text { days }\end{array}$} & \multirow{2}{*}{$\sim 20$} & \multirow{2}{*}{$\begin{array}{l}\text { CVVPa } \\
\Delta \mathrm{p}=1 \text { bar }\end{array}$} & $118.8 \pm 1.2$ & $161.7 \pm 3.2$ & $140.7 \pm 2.7$ & - & \multirow{2}{*}{ [44] } \\
\hline $\begin{array}{l}\text { Microfibrillated cellulose } \\
\text { (MFC) from native sisal fibers }\end{array}$ & & & & $0.100 \pm 0.002$ & $0.150 \pm 0.004$ & $0.090 \pm 0.001$ & - & \\
\hline $\begin{array}{l}\text { TEMPO-oxidized cellulose } \\
\text { nanofibrils with free carboxyl } \\
\text { groups (TOCN-COOH) }\end{array}$ & \multirow{2}{*}{$\begin{array}{l}\text { casting aqueous dispersions } \\
\text { of } 0.1 \%(w / v) \text { on PET film } \\
\text { followed by drying }\end{array}$} & $\sim 13$ & \multirow{2}{*}{$\begin{array}{l}\text { Differential } \\
\text { pressure }^{b}\end{array}$} & $2.02 \times 10^{-6}$ & $7.07 \times 10^{-8}$ & $4.95 \times 10^{-7}$ & $2.41 \times 10^{-5}$ & \multirow{2}{*}{ [45] } \\
\hline $\begin{array}{l}\text { TEMPO-oxidized cellulose } \\
\text { nanofibrils with sodium } \\
\text { carboxylate groups } \\
\text { (TOCN-COONa) }\end{array}$ & & $\sim 13$ & & $2.03 \times 10^{-6}$ & $1.18 \times 10^{-7}$ & $8.57 \times 10^{-7}$ & $2.46 \times 10^{-4}$ & \\
\hline Cellulose nanocrystals (CNC) & \multirow{3}{*}{$\begin{array}{l}\text { Vacuum filtration followed } \\
\text { by hot-pressing for } 20 \mathrm{~min} \\
\text { (at } 110^{\circ} \mathrm{C} \text { and } 1.1 \mathrm{MPa} \text { ) }\end{array}$} & $\sim 30$ & \multirow{3}{*}{$\begin{array}{c}\text { Differential } \\
\text { pressure }{ }^{\mathrm{b}} \\
\Delta \mathrm{p}=2 \text { bar, r.t. }\end{array}$} & - & - & - & $1.33 \times 10^{-2}$ & \multirow{3}{*}{ [12] } \\
\hline Cellulose nanofibers (CNF) & & $\sim 30$ & & - & - & - & $3.80 \times 10^{-2}$ & \\
\hline $\begin{array}{l}\text { Sulfonated cellulose } \\
\text { nanofibers (CNF) }\end{array}$ & & $\sim 30$ & & - & - & - & $1.41 \times 10^{-1}$ & \\
\hline $\begin{array}{l}\text { Carboxymethyl cellulose } \\
\text { (CMC) }\end{array}$ & $\begin{array}{l}\text { casting aqueous dispersions } \\
\text { of } 2 \% \text { on stainless-steel } \\
\text { substrate followed by } \\
\text { vacuum drying }\end{array}$ & $\mathrm{n} / \mathrm{a}$ & $\begin{array}{c}\text { CVVP }^{a} \\
\text { pure gases, } \\
\Delta \mathrm{p}=1 \text { bar }^{\mathrm{a}}\end{array}$ & $2.50 \times 10^{-5}$ & $1.02 \times 10^{-5}$ & - & $1.48 \times 10^{-4}$ & [46] \\
\hline CNF (tunicate) & \multirow{4}{*}{$\begin{array}{l}\text { casting aqueous dispersions } \\
\text { of } 0.5 \%(w / v) \text { in PS molds } \\
\text { followed by drying }\end{array}$} & 37 & \multirow{4}{*}{$\begin{array}{c}\text { Differential } \\
\text { pressure }{ }^{\mathrm{b}} \\
\Delta \mathrm{p}=2 \text { bar, r.t. }\end{array}$} & $96 \pm 0.7$ & $98.7 \pm 0.9$ & $46 \pm 4.9$ & $363.5 \pm 12.5$ & \multirow{4}{*}{ This work } \\
\hline $\mathrm{SW} / \mathrm{CNF}$ & & 22 & & $1315 \pm 6$ & $1523 \pm 7$ & $1321 \pm 19$ & $4864 \pm 45$ & \\
\hline $\mathrm{HW} / \mathrm{CNF}$ & & 22 & & $26.2 \pm 0.4$ & $27.5 \pm 0.4$ & $8.2 \pm 0.8$ & $75.8 \pm 3.4$ & \\
\hline $\mathrm{CF} / \mathrm{CNF}$ & & 24 & & $5.1 \pm 0.2$ & $4.7 \pm 0.4$ & $3.2 \pm 0.4$ & $24.6 \pm 1.3$ & \\
\hline
\end{tabular}

a CVVP - constant volume, variable pressure ("time-lag") method; ${ }^{b}$ Differential pressure method according to JISK7126A and ASTMD1434 standards. 


\section{References}

1. Thomas, B.; Raj, M.C.; Athira, B.K.; Rubiyah, H.M.; Joy, J.; Moores, A.; Drisko, G.L.; Sanchez, C. Nanocellulose, a Versatile Green Platform: From Biosources to Materials and Their Applications. Chem. Rev. 2018, 118, 11575-11625. [CrossRef] [PubMed]

2. Dufresne, A. Nanocellulose: A new ageless bionanomaterial. Mater. Today 2013, 16, 220-227. [CrossRef]

3. Selyanchyn, O.; Selyanchyn, R.; Lyth, S.M. A Review of Proton Conductivity in Cellulosic Materials. Front. Energy Res. 2020, 8 , 1-17. [CrossRef]

4. Trovagunta, R.; Zou, T.; Österberg, M.; Kelley, S.S.; Lavoine, N. Design strategies, properties and applications of cellulose nanomaterials-enhanced products with residual, technical or nanoscale lignin-A review. Carbohydr. Polym. 2021, 254. [CrossRef] [PubMed]

5. Lavoine, N.; Bergström, L. Nanocellulose-based foams and aerogels: Processing, properties, and applications. J. Mater. Chem. A 2017, 5, 16105-16117. [CrossRef]

6. Geng, S.; Wei, J.; Jonasson, S.; Hedlund, J.; Oksman, K. Multifunctional Carbon Aerogels with Hierarchical Anisotropic Structure Derived from Lignin and Cellulose Nanofibers for $\mathrm{CO}_{2}$ Capture and Energy Storage. ACS Appl. Mater. Interfaces 2020, 12, 7432-7441. [CrossRef]

7. Alammar, A.; Park, S.-H.; Ibrahim, I.; Arun, D.; Holtzl, T.; Dumée, L.F.; Lim, H.-N.; Szekely, G. Architecting neonicotinoidscavenging nanocomposite hydrogels for environmental remediation. Appl. Mater. Today. 2020, 21, 100878. [CrossRef]

8. Zheng, X.; Zhang, Y.; Bian, T.; Zhang, Y.; Li, Z.; Pan, J. Oxidized carbon materials cooperative construct ionic imprinted cellulose nanocrystals films for efficient adsorption of Dy(III). Chem. Eng. J. 2020, 381, 122669. [CrossRef]

9. Porter, C.J.; Werber, J.R.; Ritt, C.L.; Guan, Y.-F.; Zhong, M.; Elimelech, M. Controlled grafting of polymer brush layers from porous cellulosic membranes. J. Membr. Sci. 2020, 596, 117719. [CrossRef]

10. Ansaloni, L.; Salas-Gay, J.; Ligi, S.; Baschetti, M.G. Nanocellulose-based membranes for $\mathrm{CO}_{2}$ capture. J. Memb. Sci. 2017, 522, 216-225. [CrossRef]

11. Bayer, T.; Cunning, B.V.; Selyanchyn, R.; Nishihara, M.; Fujikawa, S.; Sasaki, K.; Lyth, S.M. High temperature proton conduction in nanocellulose membranes: Paper fuel cells. Chem. Mater. 2016, 28, 4805-4814. [CrossRef]

12. Bayer, T.; Cunning, B.V.; Šmíd, B.; Selyanchyn, R.; Fujikawa, S.; Sasaki, K.; Lyth, S.M. Spray deposition of sulfonated cellulose nanofibers as electrolyte membranes in fuel cells. Cellulose 2021, 0123456789. [CrossRef]

13. Quellmalz, A.; Mihranyan, A. Citric Acid Cross-Linked Nanocellulose-Based Paper for Size-Exclusion Nanofiltration. ACS Biomater. Sci. Eng. 2015, 1, 271-276. [CrossRef] [PubMed]

14. Gellerstedt, G.L.F.; Henriksson, E.G. Lignins: Major sources, structure and properties. In Monomers, Polymers and Composites from Renewable Resources; Elsevier: Amsterdam, The Netherlands, 2008; pp. 201-224. ISBN 9780080453163. [CrossRef]

15. Adler, E. Lignin Chemistry-Past, Present, and Future. Wood. Sci. Technol. 1976, 8, 1-25. [CrossRef]

16. Schuetz, M.; Benske, A.; Smith, R.A.; Watanabe, Y.; Tobimatsu, Y.; Ralph, J.; Demura, T.; Ellis, B.; Samuels, A.L. Laccases direct lignification in the discrete secondary cell wall domains of protoxylem. Plant Physiol. 2014, 166, 798-807. [CrossRef] [PubMed]

17. Balakshin, M.Y.; Capanema, E.A.; Sulaeva, I.; Schlee, P.; Huang, Z.; Feng, M.; Borghei, M.; Rojas, O.J.; Potthast, A.; Rosenau, T. New Opportunities in the Valorization of Technical Lignins. ChemSusChem 2020, 1016-1036. [CrossRef]

18. Dessbesell, L.; Paleologou, M.; Leitch, M.; Pulkki, R.; Xu, C. (Charles) Global lignin supply overview and kraft lignin potential as an alternative for petroleum-based polymers. Renew. Sustain. Energy Rev. 2020, 123. [CrossRef]

19. Farooq, M.; Zou, T.; Riviere, G.; Sipponen, M.H.; Österberg, M. Strong, Ductile, and Waterproof Cellulose Nanofibril Composite Films with Colloidal Lignin Particles. Biomacromolecules 2019, 20, 693-704. [CrossRef] [PubMed]

20. Dou, J.; Bian, H.; Yelle, D.J.; Ago, M.; Vajanto, K.; Vuorinen, T.; Zhu, J. Lignin containing cellulose nanofibril production from willow bark at $80^{\circ} \mathrm{C}$ using a highly recyclable acid hydrotrope. Ind. Crops Prod. 2019, 129, 15-23. [CrossRef]

21. Saha, D.; Van Bramer, S.E.; Orkoulas, G.; Ho, H.C.; Chen, J.; Henley, D.K. CO2 capture in lignin-derived and nitrogen-doped hierarchical porous carbons. Carbon N. Y. 2017, 121, 257-266. [CrossRef]

22. Xu, C.; Strømme, M. Sustainable porous carbon materials derived from wood-based biopolymers for CO2 capture. Nanomaterials 2019, 9, 103. [CrossRef]

23. Zhao, Y.; Tagami, A.; Dobele, G.; Lindström, M.E.; Sevastyanova, O. The impact of lignin structural diversity on performance of cellulose nanofiber (CNF)-starch composite films. Polymers 2019, 11, 538. [CrossRef]

24. Tomani, P. The lignoboost process. Cellul. Chem. Technol. 2010, 44, 53-58.

25. Tagami, A.; Gioia, C.; Lauberts, M.; Budnyak, T.; Moriana, R.; Lindström, M.E.; Sevastyanova, O. Solvent fractionation of softwood and hardwood kraft lignins for more efficient uses: Compositional, structural, thermal, antioxidant and adsorption properties. Ind. Crop. Prod. 2019, 129, 123-134. [CrossRef]

26. Abbadessa, A.; Oinonen, P.; Henriksson, G. Characterization of Two Novel Bio-based Materials from Pulping Process Side Streams: Ecohelix and CleanFlow Black Lignin. BioResources 2018, 13, 7606-7627. [CrossRef]

27. Heitner, C.; Dimmel, D.; Schmidt, J. Lignin and Lignans: Advances in Chemistry; CRC press: Boca Raton, FL, USA, 2016.

28. Zhao, W.W.; Xiao, L.P.; Song, G.Y.; Sun, R.C.; He, L.L.; Singh, S.; Simmons, B.A.; Cheng, G. From lignin subunits to aggregates: Insights into lignin solubilization. Green Chem. 2017, 19, 3272-3281. [CrossRef]

29. Pylypchuk, I.V.; Lindén, P.A.; Lindström, M.E.; Sevastyanova, O. New Insight into the Surface Structure of Lignin Nanoparticles Revealed by $1 \mathrm{H}$ Liquid-State NMR Spectroscopy. ACS Sustain. Chem. Eng. 2020, 8, 13805-13812. [CrossRef] 
30. Oveissi, F.; Fatehi, P. Characterization of four different lignins as a first step toward the identification of suitable end-use applications. J. Appl. Polym. Sci. 2015, 132,1-9. [CrossRef]

31. Chen, C.; Petterson, T.; Illergård, J.; Ek, M.; Wågberg, L. Influence of Cellulose Charge on Bacteria Adhesion and Viability to PVAm/CNF/PVAm-Modified Cellulose Model Surfaces. Biomacromolecules 2019, 20, 2075-2083. [CrossRef] [PubMed]

32. Wulandari, W.T.; Rochliadi, A.; Arcana, I.M. Nanocellulose prepared by acid hydrolysis of isolated cellulose from sugarcane bagasse. IOP Conf. Ser. Mater. Sci. Eng. 2016, 107. [CrossRef]

33. Larkin, P.J. (Ed.) Illustrated IR and Raman Spectra Demonstrating Important Functional Groups. In Infrared and Raman Spectroscopy, 2nd ed.; Elsevier: Amsterdam, The Netherlands, 2018; pp. 153-210, ISBN 9780128041628. [CrossRef]

34. Ribca, I.; Jawerth, M.E.; Brett, C.J.; Lawoko, M.; Schwartzkopf, M.; Chumakov, A.; Roth, S.V.; Johansson, M. Exploring the Effects of Different Cross-Linkers on Lignin-Based Thermoset Properties and Morphologies. ACS Sustain. Chem. Eng. 2021. [CrossRef]

35. Herrera, M.; Thitiwutthisakul, K.; Yang, X.; Rujitanaroj, P.-O.; Rojas, R.; Berglund, L. Preparation and evaluation of high-lignin content cellulose nanofibrils from eucalyptus pulp. Cellulose 2018, 25, 3121-3133. [CrossRef]

36. Sing, K.S.W.; Williams, R.T. Physisorption hysteresis loops and the characterization of nanoporous materials. Adsorpt. Sci. Technol. 2004, 22, 773-782. [CrossRef]

37. Shields, J.E.; Lowell, S.; Thomas, M.A.; Thommes, M. Characterization of Porous Solids and Powders: Surface Area, Pore Size and Density; Kluwer Academic Publisher: Boston, MA, USA, 2004; pp. 43-45.

38. Barret, E.P.; Joyner, L.G.; Halenda, P.P. The Determination of Pore Volume and Area Distributions in Porous Substances. I. Computations from Nitrogen Isotherms. J. Am. Chem. Soc. 1951, 73, 373-380. [CrossRef]

39. Wijmans, J.; Baker, R. The Solution-Diffusion Model-A Review. JMS 1995, 107, 1-21. [CrossRef]

40. Baker, R.W. (Ed.) Membrane Transport Theory. In Membrane Technology and Applications, 3rd ed.; Wiley: Hoboken, NJ, USA, 2012; ISBN 978-0-470-74372.

41. Liang, M.; Liu, Y.; Xiao, B.; Yang, S.; Wang, Z.; Han, H. An analytical model for the transverse permeability of gas diffusion layer with electrical double layer effects in proton exchange membrane fuel cells. Int. J. Hydrog. Energy 2018, 43, 17880-17888. [CrossRef]

42. Xiao, B.; Wang, W.; Zhang, X.; Long, G.; Fan, J.; Chen, H.; Deng, L. A novel fractal solution for permeability and Kozeny-Carman constant of fibrous porous media made up of solid particles and porous fibers. Powder Technol. 2019, 349, 92-98. [CrossRef]

43. Belbekhouche, S.; Bras, J.; Siqueira, G.; Chappey, C.; Lebrun, L.; Khelifi, B.; Marais, S.; Dufresne, A. Water sorption behavior and gas barrier properties of cellulose whiskers and microfibrils films. Carbohydr. Polym. 2011, 83, 1740-1748. [CrossRef]

44. Fukuzumi, H.; Fujisawa, S.; Saito, T.; Isogai, A. Selective permeation of hydrogen gas using cellulose nanofibril film. Biomacromolecules 2013, 14, 1705-1709. [CrossRef]

45. Zhang, F.; Dou, J.; Zhang, H. Mixed membranes comprising carboxymethyl cellulose (as capping agent and gas barrier matrix) and nanoporous ZIF-L nanosheets for gas separation applications. Polymers 2018, 10, 1340. [CrossRef]

46. Selyanchyn, R.; Fujikawa, S. Membrane thinning for efficient $\mathrm{CO}_{2}$ capture. Sci. Technol. Adv. Mater. 2017, 18, 816-827. [CrossRef] [PubMed] 